\title{
Simplified Space Vector Pulse Width Modulation based on Switching Schemes with Reduced Switching Frequency and Harmonics for Five Level Cascaded H-bridge Inverter
}

\author{
B. Sirisha, P. Satishkumar \\ Department of EEE, University College of Engineering, Osmania University, India
}

\begin{tabular}{l} 
Article Info \\
Article history: \\
Received Dec 23, 2017 \\
Revised Mar 20, 2018 \\
Accepted Mar 28, 2018 \\
\hline Keyword: \\
Cascaded H-bridgeinverter \\
Multilevel inverter \\
SVPWM \\
Switching sequence \\
THD
\end{tabular}

THD

\begin{abstract}
This paper presents a simplified control strategy of spacevector pulse width modulation technique with a three segment switching sequence and seven segment switching sequence for high power applications of multilevel inverters. In the proposed method, the inverter switching sequences are optimized for minimization of device switching frequency and improvement of harmonic spectrum by using the three most desired switching states and one suitable redundant state for each space vector. The proposed threesegment sequence is compared with conventional seven-segment sequence for five level Cascaded H-Bridge inverter with various values of switching frequencies including very low frequency. The output spectrum of the proposed sequence design shows the reduction of device switching frequency, current and line voltage THD, thereby minimizing the filter size requirement of the inverter, employed in industrial applications, where sinusoidal output voltage is required.
\end{abstract}

Copyright $\odot 2018$ Institute of Advanced Engineering and Science. All rights reserved.

Corresponding Author:

B. Sirisha,

Department of Electrical Engineering,

Osmania University,

Hyderabad, India.

Email: sirishab2007@yahoo.com

\section{INTRODUCTION}

With ever increasing demand, of electrical energy and depleting fossil fuel reserves, the efficiency utilization of existing resources have become compelling requirement. High efficiency power electronic converter topologies with optimized control strategies are required to minimize the energy waste and improve the power quality. The design of controlled medium voltage drives is faced with challenges that relate to the topologies and control of the and motor side converters. The voltage and currents wave forms are effected by factors like topology used the control algorithm the filter size, choice of switching frequency and the application .The switching on of medium voltage semi conductor devices also make up the major part of device losses, their reduction allows the maximum output power while the other side the reduction of switching frequency causes the increased harmonic distortion of motor side waveforms. Thus the area need careful consideration for efficient drive system[1]. Multi level converter after many advantages like good power quality, low switching losses, high voltage capability, low dv/dt stress [2].

The three bench mark topologies for high power medium voltage applications are neutral point clamped, series cascaded H-bridge, flying capacitor converter cascaded H bridge VSC has been applied for high power and power quality industrial requirement due to it series expansion capabilities in industrial main applications include, active filter, reactive power compensation, electric vehicles photo voltaic power conversion, ups etc. this topology can be operated at different switching frequencies for different application [3]. The H-bridge is supplied by isolated d.c. sources, composed of multiphase diode rectifiers. Among the various switching algorithms. Proposed in the literature for multi level converters, SVM is the most 
promising one, which offers greatest flexibility in optimizing the switching pattern design and also well suited for digital implementation [4]. SVM with 7-segment sequence is generally used for 2-level and 3-level inverter topologies. For higher level inverter because of difficulty due to overwhelming complexity of switching sequence design and heavy relative compilation load. The compilation load have been successfully reduced by simplifying the required calculation of reference vector location duty cycle calculation. These are number of publications in the literature covering various aspects such as neutral point stabilization over modulation common mode voltage reduction SVM [5]-[13]. The main focus of this paper is on the implementation of switching sequence design. This paper presents simplified and generalized SVM algorithm with 3-segment and 7-segment switching sequence inducing over modulation operation to improve the output voltage spectrum by minimizing the device switching frequency. The performance of the proposed sequence design is analyzed through extensive simulations for five level Cascaded H-bridge inverter.

\section{SPACE VECTOR MODULATION METHOD}

For a typical three, five, and seven-level cascaded H-bridge inverter, with a separate dc power supply is used for each $\mathrm{H}$ - Bridge. Its corresponding space voltage vector diagram is illustrated in Figure 1. For the 5-level inverter, there are 96 small triangles and the vertex of each triangle represents a space vector. The hexagonal vectors can be divided into six major triangular sectors (I to VI). Only the first sector of the coordinate is used because the vectors located in the other sectors can be transformed to first sector by clockwise rotating by an angle of $\mathrm{k} * \mathrm{pi} / 3, \mathrm{k}=(1,2,3,4,5$ for sector 2 to 6$)$. As all the sectors are identical, only details of sector 1 is given in Figure 2 .

For N-level inverter there are N3 switching states that lie over $6(\mathrm{~N}-1)^{2}$ triangles. Figure 2 gives the representation of all the space vectors of the inverter in $60^{\circ}$ co-ordinate system, the location of the reference vector is identified according to the condition given in Table 1 and all the coordinates are obtained and dwell times are calculated based on volt-second balance principle. After identifying all the switching states, out of many redundant states desired and suitable redundant states are utilized for the sequence, in the implementation of the proposed switching sequence the most desired switching state along with suitable redundant state are utilized based on the nature of the co-ordinates $(\mathrm{g}, \mathrm{h})$ of the reference vector the triangles are classified as Type-I, Type-II and Type-III.

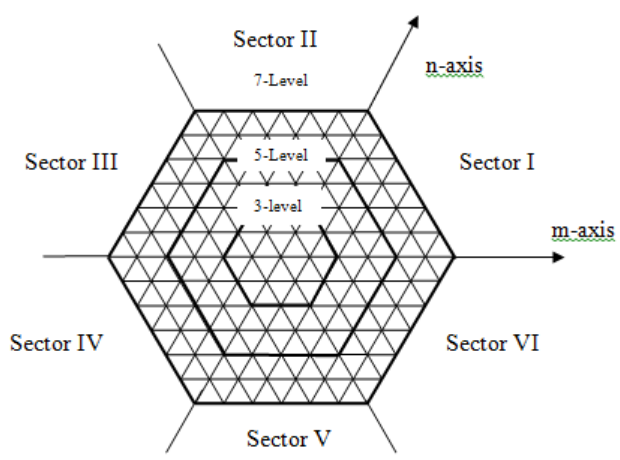

Figure 1. Voltage vectors of 3,5 and 7 - level voltage source inverters

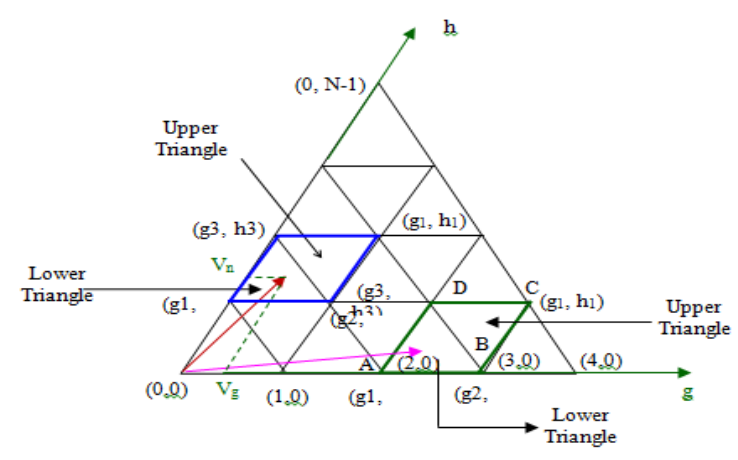

Figure 2. Voltage vectors in $60^{\circ}$ co-ordinate system of five level inverter

Table 1. Determination of triangle of Reference Vector

\begin{tabular}{cc}
\hline$\left(V_{g}+V_{h}\right)>(g+h+1)$ & $\left(V_{g}+V_{h}\right) \leq(g+h+1)$ \\
\hline Reference Vector lies in triangle BDA & Reference Vector lies in triangle CBD \\
$g_{1}=g+1 ; h_{1}=h+1$ & $g_{1}=g ; h_{1}=h$ \\
$g_{2}=g+1 ; h_{2}=h$ & $g_{2}=g+1 ; h_{2}=h$ \\
$g_{3}=g ; h_{3}=h+1$ & $g_{3}=g ; h_{3}=h+1$ \\
\hline
\end{tabular}

$$
g_{1} T_{1}+g_{2} T_{2}+g_{3} T_{3}=T_{r e f} V_{g}
$$




$$
\begin{aligned}
& h_{1} T_{1}+h_{2} T_{2}+h_{3} T_{3}=T_{r e f} V_{h} \\
& T_{1}+T_{2}+T_{3}=T_{r e f}
\end{aligned}
$$

All the triangles of the space vector diagram are classified as Type-I, II, and III based on the integer coordinates of the reference vector in $60^{\circ}$ axis and are given as:

Type-I: where both $(\mathrm{g}, \mathrm{h})$ are odd or even the three most desired states for the three vertices of $(\mathrm{g} 1, \mathrm{~h} 1)$ $(\mathrm{g} 2, \mathrm{~h} 2)(\mathrm{g} 3, \mathrm{~h} 3)$ are $\left([\mathrm{SRi}, \mathrm{SYi}, \mathrm{SBi}]_{\mathrm{i}=1,2,3}\right)$ and one redundant state $S_{j r}^{\prime}=\left[\mathrm{S}_{\mathrm{Rr}}^{\prime}, \mathrm{S}_{\mathrm{Yr}}^{\prime}, \mathrm{S}_{\mathrm{Br}}^{\prime}\right\rfloor_{r=2}$ that exists for space vector (g2,h2).

Type-II: for the location of reference vector $\mathrm{Vr}$ is $\mathrm{g} 1$ is even and $\mathrm{h} 1$ is odd, the three most desired states are $\left([\mathrm{SRi}, \mathrm{SYi}, \mathrm{SBi}]_{\mathrm{i}=1,2,3}\right)$ and the redundant state $S_{j r}^{\prime}=\left[\mathrm{S}_{\mathrm{Rr}}^{\prime}, \mathrm{S}_{\mathrm{Yr}}^{\prime}, \mathrm{S}_{\mathrm{Br}}^{\prime}\right]_{\mathrm{r}=1}$ for the space vector $(\mathrm{g} 1, \mathrm{~h} 1)$.

Type-III: if $\mathrm{g} 1$ is odd and $\mathrm{h} 1$ is even the most desired state $\left([\mathrm{SRi}, \mathrm{SYi}, \mathrm{SBi}]_{\mathrm{i}=1,2,3}\right)$ and the redundant state $S_{j r}^{\prime}=\left[\mathrm{S}_{\mathrm{Rr}}^{\prime}, \mathrm{S}_{\mathrm{Yr}}^{\prime}, \mathrm{S}_{\mathrm{Br}}^{\prime}\right]_{\mathrm{r}=1}$ for the space vector $(\mathrm{g} 1, \mathrm{~h} 1)$.

\section{SWITCHING SEQUENCE DESIGN}

The unique switching stator in each triangle are determined using three most desired switching states $\left(\left|S_{\mathrm{ji}}\right|_{i=1,2,3}\right)$ and one switching redundant state $\left(S_{j r}^{\prime}=\left[S_{\mathrm{Rr}}^{\prime}, S_{\mathrm{Yr}}^{\prime}, S_{\mathrm{Br}}^{\prime}\right]_{\mathrm{r}=1,2,3}\right)$ are utilized for implement 7 segment and 3-segment switching sequence.

In conventional SVM Seven-segment switching sequence is implemented for two level or 3-level SVM but for real time because of increased computational burden because of large number of switching states of multilevel inverter implementation for higher level becomes overwhelming. In the proposed SVPWM method the optimum switching states are selected for the sequence such that there will be only one voltage level charges per commutation. The Generalised seven segment switching sequence for different types of triangles is:

Type-I: The sequence for Type-I triangles are

$$
\left[S _ { j 2 } ( \frac { T _ { 2 } } { 4 } ) \rightarrow \left[S _ { j 1 } ( \frac { T _ { 1 } } { 2 } ) \rightarrow \left[S _ { j 3 } ( \frac { T _ { 3 } } { 2 } ) \rightarrow \left[S _ { j 2 } ^ { \prime } ( \frac { T _ { 2 } } { 2 } ) \rightarrow \left[S _ { j 3 } ( \frac { T _ { 3 } } { 2 } ) \rightarrow \left[S _ { j 1 } ( \frac { T _ { 1 } } { 2 } ) \rightarrow \left[S_{j 2}\left(\frac{T_{2}}{4}\right)_{(4)}\right.\right.\right.\right.\right.\right.\right.
$$

Type-II: The sequence for Type-II triangles are

$$
\left[S_{j 1}\right]\left(\frac{T_{1}}{4}\right) \rightarrow\left[S _ { j 2 } ( \frac { T _ { 2 } } { 2 } ) \rightarrow \left[S _ { j 3 } ( \frac { T _ { 3 } } { 2 } ) \rightarrow \left[S _ { j 1 } ^ { \prime } ( \frac { T _ { 1 } } { 2 } ) \rightarrow [ S _ { j 3 } ] ( \frac { T _ { 3 } } { 2 } ) \rightarrow \left[S _ { j 2 } ( \frac { T _ { 2 } } { 2 } ) \rightarrow \left[S_{j 1}\left(\frac{T_{1}}{4}\right)\right.\right.\right.\right.\right.
$$

Type-III: The sequence for Type-III triangles are

$$
\left[S _ { j 1 } ( \frac { T _ { 1 } } { 4 } ) \rightarrow \left[S _ { j 3 } ( \frac { T _ { 3 } } { 2 } ) \rightarrow \left[S _ { j 2 } ( \frac { T _ { 2 } } { 2 } ) \rightarrow \left[S _ { j 1 } ^ { \prime } ( \frac { T _ { 1 } } { 2 } ) \rightarrow \left[S _ { j 2 } ( \frac { T _ { 2 } } { 2 } ) \rightarrow \left[S _ { j 3 } ( \frac { T _ { 3 } } { 2 } ) \rightarrow \left[S_{j 1}\left(\frac{T_{1}}{4}\right)\right.\right.\right.\right.\right.\right.\right.
$$

Generalized three or five segment switching sequence consisting of three most desired states [Sji]i=1,2,3 of three types of triangle is expressed as

Type-1: The sequence for Type-I triangles are

$$
\left[S _ { j 2 } ( \frac { T _ { 2 } } { 2 } ) \rightarrow \left[S _ { j 1 } ( \frac { T _ { 1 } } { 2 } ) \rightarrow [ S _ { j 3 } ] ( T _ { 3 } ) \rightarrow \left[S _ { j 1 } ( \frac { T _ { 1 } } { 2 } ) \rightarrow \left[S_{j 2}\left(\frac{T_{2}}{2}\right)\right.\right.\right.\right.
$$


Type-II: The sequence for Type-II triangles are

$$
\left[S_{j 1}\right]\left(\frac{T_{1}}{2}\right) \rightarrow\left[S _ { j 2 } ( \frac { T _ { 2 } } { 2 } ) \rightarrow [ S _ { j 3 } ] ( T _ { 3 } ) \rightarrow \left[S _ { j 2 } ( \frac { T _ { 2 } } { 2 } ) \rightarrow \left[S_{j 1}\left(\frac{T_{1}}{2}\right)\right.\right.\right.
$$

Type-III: The sequence for Type-III triangles are

$$
\left[S_{j 1}\right]\left(\frac{T_{1}}{2}\right) \rightarrow\left[S_{j 3}\right]\left(\frac{T_{3}}{2}\right) \rightarrow\left[S_{j 2}\right]\left(T_{3}\right) \rightarrow\left[S_{j 3}\right]\left(\frac{T_{3}}{2}\right)\left[S_{j 1}\right]\left(\frac{T_{1}}{2}\right)
$$

In three-segment switching sequence the leading and trailing state over a switches period is same as sevensegment switching sequence.

\section{CALCULATION OF SWITCHING FREQUENCY}

For any multilevel inverter the switching devices may not have the same device switching frequencies. The average switching frequency is defined as total number of switching of all the switches per second to the number of active devices of the inverter ( $\mathrm{F}$ avg $\_\mathrm{sw}$ )

$\left.\mathrm{f}_{\left(\text {avg } \_ \text {sw }\right.}\right)=\mathrm{F}_{\text {(ideal }- \text { Avg_sw) }}$, If leading state of the next sequence is equal to trailing state of the proceeding sequence.

$$
F_{\text {ideal-Avg-Sw }}=\frac{\left(N_{p h}\right)\left(N_{s}\right) f s}{N}
$$

Nph - Number of commutating phases

Ns - Number of complete switching actions ('on' and 'off' transition) per phase

$\mathrm{N}$ - Number of devices per commutation

fs $=$ switching frequency

Table 2. Frequency Components for Seven-segment and Three-segment Switching Patters for Five Level Cascaded Inverter

\begin{tabular}{lcc}
\hline & $\begin{array}{c}\text { Frequency components of different switching patterns } \\
\text { F-segment-switcing sequence }\end{array}$ & 3-segment-switching sequence \\
\hline $\begin{array}{l}\mathrm{F}_{\text {(ideal-avg-sw) }} \\
\text { Equivalent inverter frequency }\end{array}$ & $\frac{(3 \times 1) \times 2 f s}{24}=\frac{f s}{4}$ & $\frac{2 \times\left(\frac{1}{2}\right) \times 2 f s}{24}=\frac{f s}{12}$ \\
\hline
\end{tabular}

For the same ideal average switching frequency, the inverter equivalent frequency for three-segment will be double that of seven-segment sequence $(50 \%$ more). For the same inverter equivalent frequency, the ideal average switching frequency for three segment is equal to two third of the corresponding seven-segment sequence number of extra commutations also increases the device frequency and average switching frequency.

\section{RESULTS AND DISCUSSIONS}

The performance of the above switching sequences for SVPWM technique is evaluated for Five level cascaded H- Bridge Inverter with DC input voltage of $100 \mathrm{~V}$. Corresponding to the modulation index of 0.87 . The parameters of Induction motor for simulation are, stator resistance $(\mathrm{Rs})=2.3 \Omega$, rotor resistance $(\mathrm{Rr})$ $=2.5 \Omega$, statorleakageinductance $=0.28 \mathrm{H}$, mutualinductance $=0.24 \mathrm{H}$, Numberofpoles $=4$, ratedfrequency $=50 \mathrm{~Hz}$, Moment of inertia $=0.0025 \mathrm{~J}$, Damping coefficient $(\mathrm{B})=0.000124$. From Table 3 it is shown that for the same inverter switching frequency the ideal average switching frequency for three segment switching sequence is $2 / 3$ of the ideal average switching frequency for seven segment switching sequence. From Table 4 it is shown that for the same ideal average switching frequency, the inverter switching frequency for three segment switching sequence is $50 \%$ higher than that of seven segment switching sequence. 
Table 3. Ideal Average Device Frequency of Seven-segment and Three-segment Switching Sequences for different Switching Frequencies

\begin{tabular}{ccc}
\hline $\begin{array}{c}\text { Inverter Equivalent } \\
\text { Frequency in Hz }\end{array}$ & $\begin{array}{c}\text { Ideal Average device frequency of } \\
\text { seven-segment switching sequence } \mathrm{F}_{\text {(ideal- }} \\
\text { avg-sw) } \\
\text { in Hz }\end{array}$ & $\begin{array}{c}\text { Ideal Average device frequency of three- } \\
\text { segment switching sequence } \\
\mathrm{F}_{(\text {ideal-avg-sw) }} \text { in Hz }\end{array}$ \\
\hline 600 & 150 & 100 \\
900 & 225 & 150 \\
1050 & 262 & 175 \\
2100 & 525 & 350 \\
3000 & 750 & 500 \\
\hline
\end{tabular}

Table 4. Inverter Equivalent Frequency of Seven-segment and Three-segment Switching Sequences for different Ideal Average Device Switching Frequencies

\begin{tabular}{ccc}
$\begin{array}{c}\text { Ideal Average device frequency of } \\
\text { seven-segment switching sequence } \\
\mathrm{F}_{\text {(ideal-avg-sw) }} \text { in Hz }\end{array}$ & $\begin{array}{c}\text { Inverter Equivalent Frequency of } \\
\text { seven-segment switching sequence } \\
\mathrm{F}_{\text {(ideal-avg-sw) }} \text { in Hz }\end{array}$ & $\begin{array}{c}\text { Inverter Equivalent Frequency of three- } \\
\text { segment switching sequence } \\
\mathrm{F}_{(\text {ideal-avg-sw) }}\end{array}$ \\
\hline 150 & & 600 \\
225 & 900 & 900 \\
262 & 1050 & 1350 \\
525 & 2100 & 3150 \\
750 & 3000 & 4500 \\
\hline
\end{tabular}

Figure 3 gives the line voltage spectrum over broder range $(12500 \mathrm{~Hz})$ with inverter switching frequency of $2100 \mathrm{~Hz}$. The harmonics appear as side band around inverter equivalent frequency. The ideal average device switching frequency being $525 \mathrm{~Hz}$. The THD obtained for seven-segment sequence is $19.41 \%$. Figure 4 gives the line voltage spectrum over broder range $(12500 \mathrm{~Hz})$ with inverter switching frequency of $3150 \mathrm{~Hz}$. For the same ideal average device switching frequency (525), the inverter is simulated for threesegment switching sequence. The harmonics appear as side band around inverter equivalent frequency of $3150 \mathrm{~Hz}$. The magnitude of harmonics is reduced to larger amount giving lesser value of THD which is $16.32 \%$. Figure 5 shows the line voltage spectrum of five level cascaded inverter over $12.5 \mathrm{KHz}$ with threesegment switching sequence with switching frequency of $4745 \mathrm{~Hz}$.
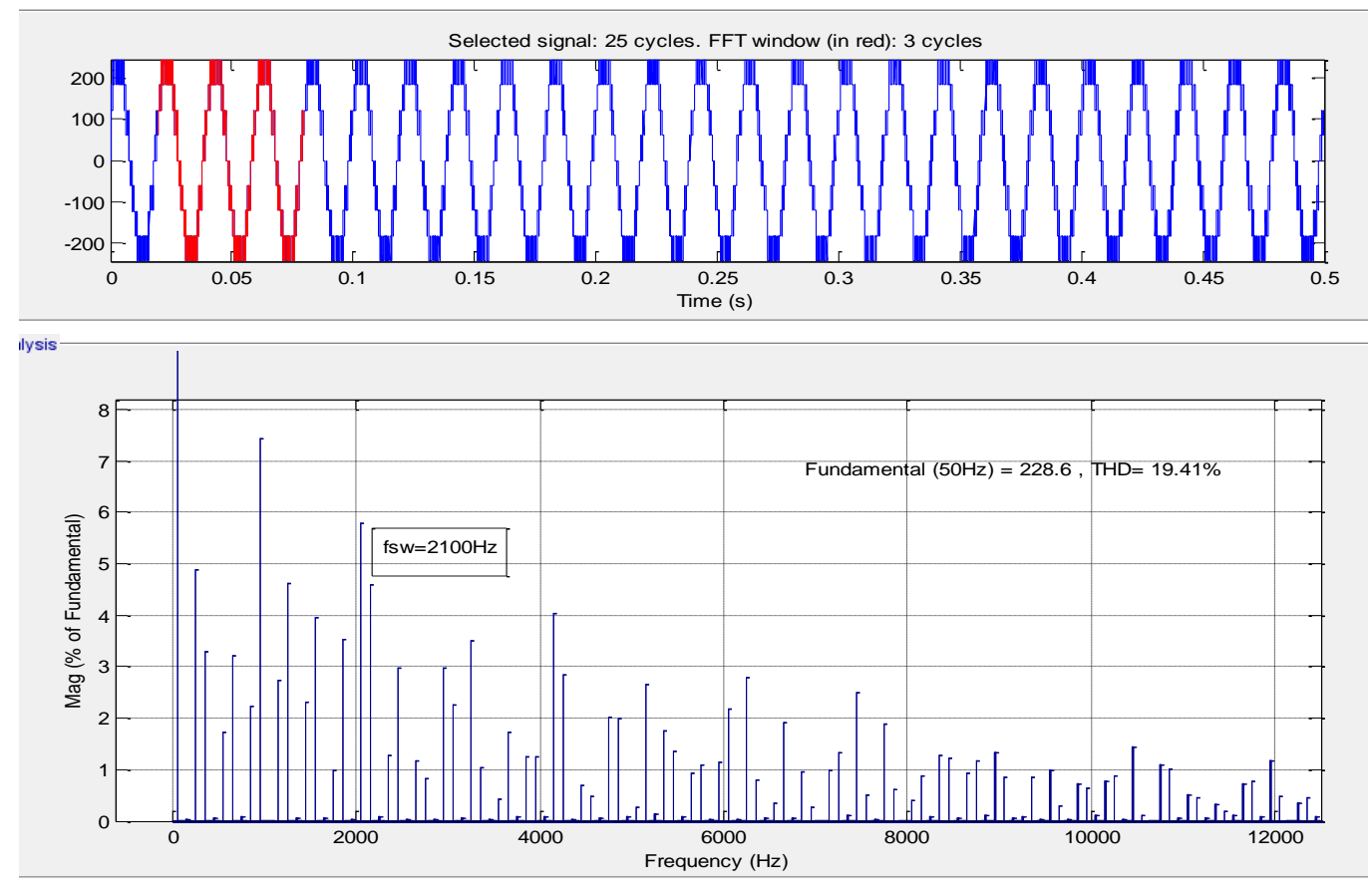

Figure 3. Line Voltage spectrum of five level cascaded inverter over $12.5 \mathrm{KHz}$ with seven-segment switching sequence 

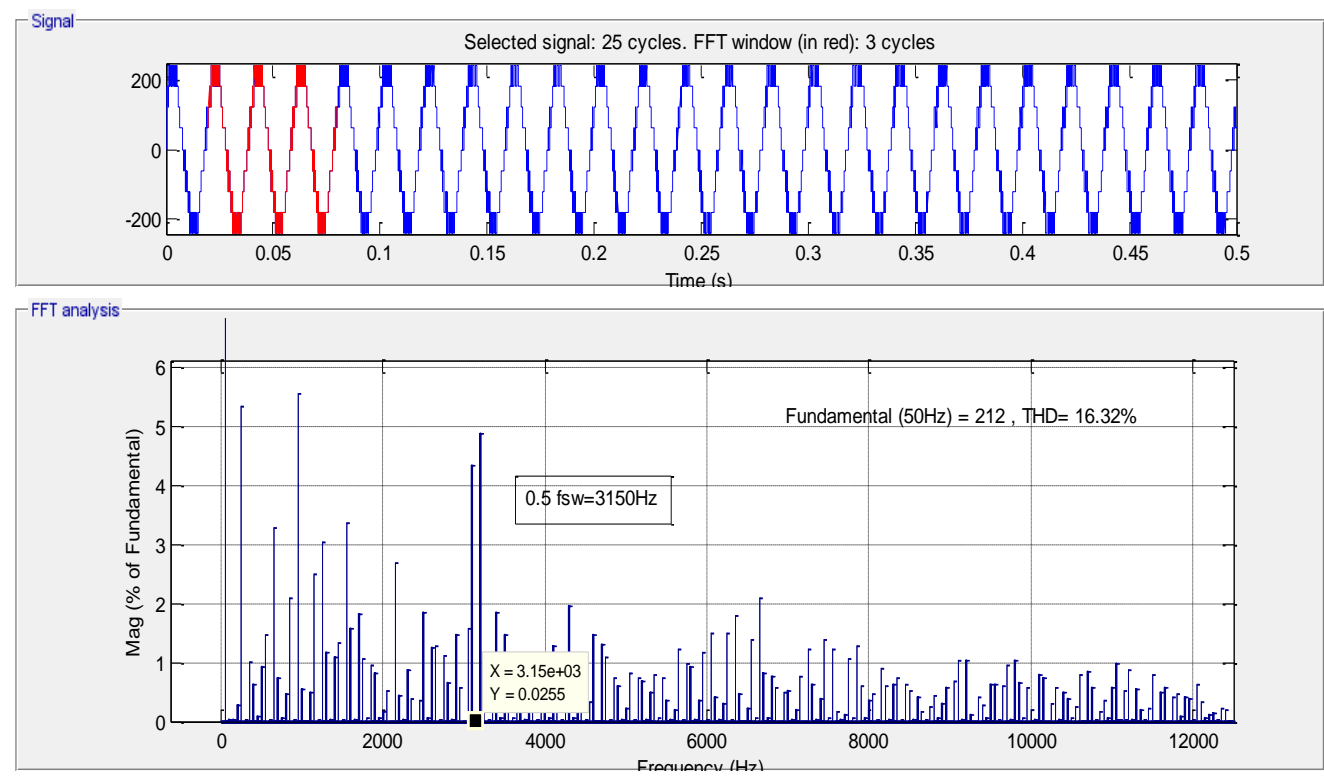

Figure 4. Line Voltage spectrum of five level cascaded inverter over $12.5 \mathrm{KHz}$ with three-segment switching sequence for switching frequency of $3150 \mathrm{~Hz}$
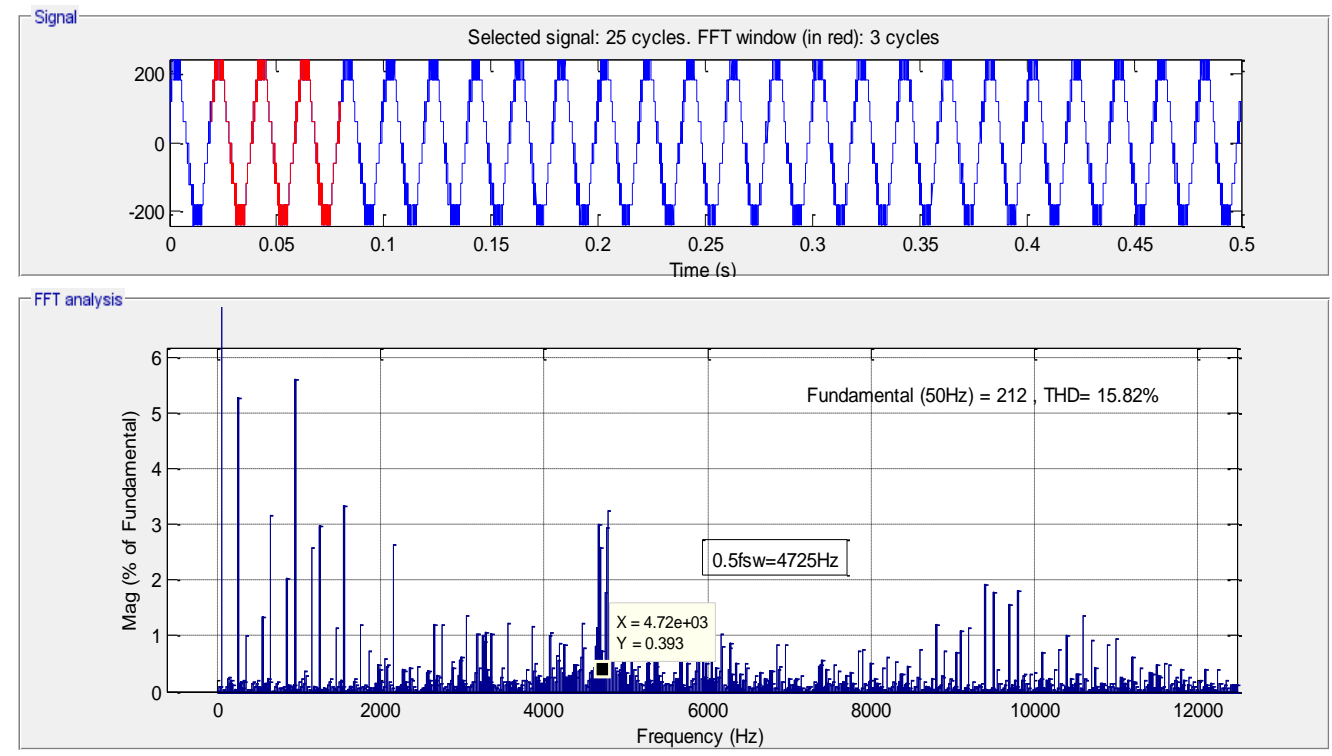

Figure 5. Line Voltage spectrum of five level cascaded inverter over $12.5 \mathrm{KHz}$ with three-segment switching sequence with switching frequency of $4745 \mathrm{~Hz}$

Figure 6 gives the line voltage spectrum over broder range $(12500 \mathrm{~Hz})$ with inverter switching frequency of $1125 \mathrm{~Hz}$. The harmonics appear as side band around inverter equivalent frequency (switching frequency). The THD obtained is $16.92 \%$.

Figure 7 gives the line voltage spectrum over broder range $(12500 \mathrm{~Hz})$ with inverter switching frequency of $750 \mathrm{~Hz}$. For the same ideal average device switching frequency $(187 \mathrm{~Hz})$, the inverter is simulated for seven-segment switching sequence. The harmonics appear as side band around inverter equivalent frequency of $750 \mathrm{~Hz}$. From Figure 8 it is shown that the phase voltage THD increases at higher inverter frequencies in case of three- segment switching pattern compared to seven - segment switching pattern. Table 5 shows the THD of line phase and current of five level cascaded inverter for seven-segment 
switching sequence. Table 6 shows the THD of line phase and current of five level cascaded inverter for three-segment switching sequence.

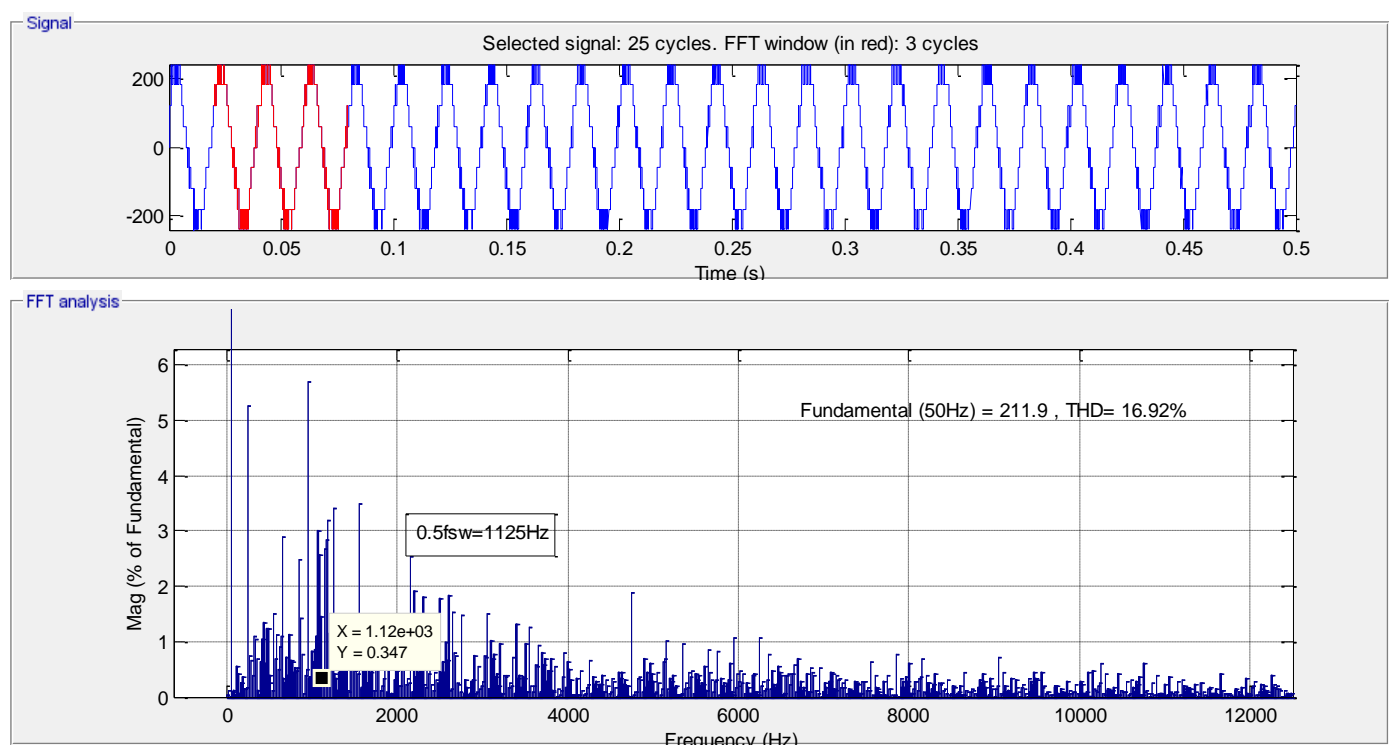

Figure 6. Line Voltage spectrum of five level cascaded inverter over $12.5 \mathrm{KHz}$ with three-segment switching sequence with switching frequency of $1125 \mathrm{~Hz}$

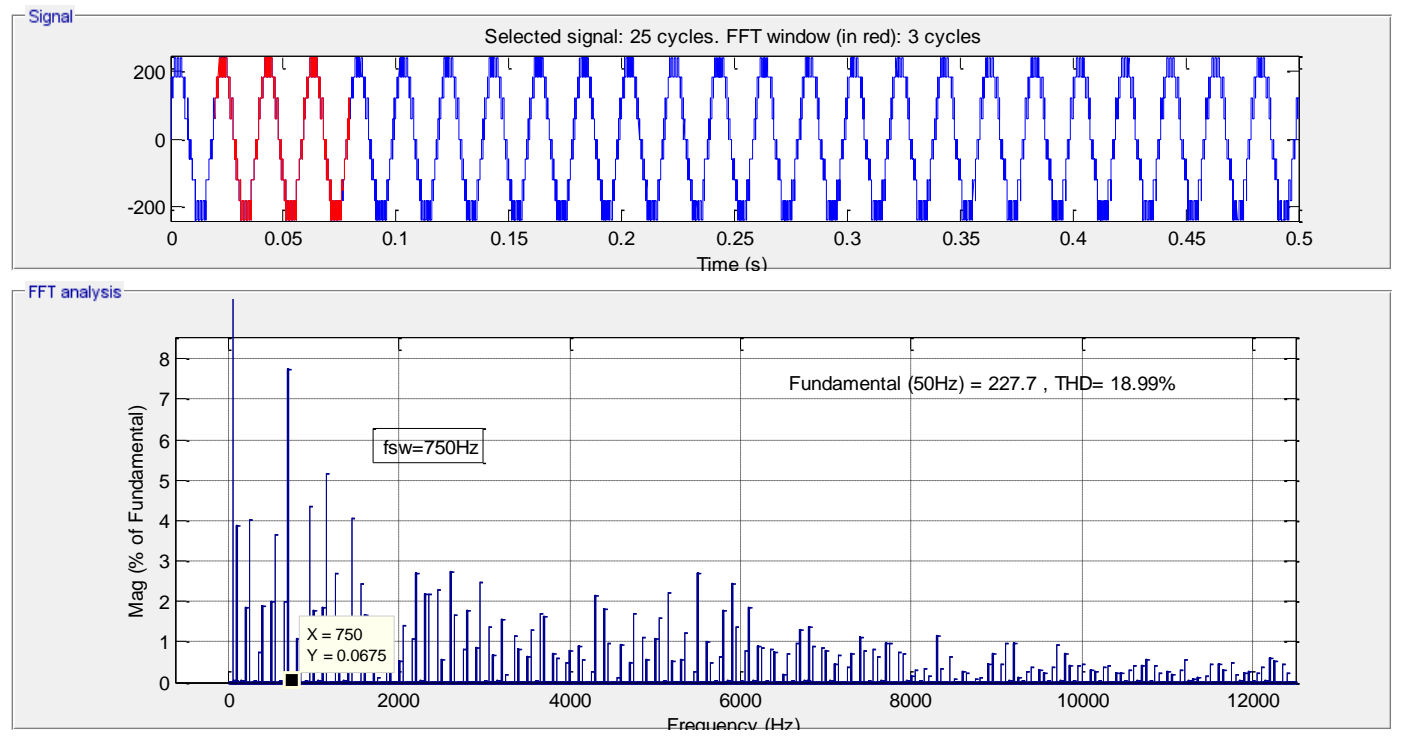

Figure 7. Line Voltage spectrum of five level cascaded inverter over $12.5 \mathrm{KHz}$ with seven-segment switching sequence with switching frequency of $750 \mathrm{~Hz}$

Table 5. THD of Line Phase and current of five level Cascaded Inverter for Seven-segment Switching

\begin{tabular}{cccc}
\multicolumn{4}{c}{ Sequence } \\
\hline $\begin{array}{c}\text { Inverter switching } \\
\text { Frequency }\end{array}$ & $\begin{array}{c}\mathrm{V}_{\mathrm{L}} \text { Line voltage THD } \\
\text { As a \% of fundamental }\end{array}$ & $\begin{array}{c}\mathrm{V}_{\text {Ph Line voltage THD }} \text { As a \% of fundamental } \\
\text { As a \% of fundamental }\end{array}$ & $\begin{array}{c}\text { I(current) THD } \\
\text { As }\end{array}$ \\
\hline 600 & 12.04 & 23.51 & 5.39 \\
900 & 12.62 & 33.41 & 5.07 \\
1050 & 11.29 & 27.08 & 5.66 \\
2100 & 11.39 & 29.03 & 5.04 \\
3000 & 10.34 & 26.64 & 5.35 \\
4200 & 10.24 & 26.73 & 5.46 \\
\hline
\end{tabular}


Table 6. THD of Line Phase and Current of Five Level Cascaded Inverter for Three-segment Switching Sequence

\begin{tabular}{cccc}
\hline $\begin{array}{c}\text { Inverter switching } \\
\text { Frequency }\end{array}$ & $\begin{array}{c}\mathrm{V}_{\mathrm{L}} \text { Line voltage THD } \\
\text { As a \% of fundamental }\end{array}$ & $\begin{array}{c}\mathrm{V}_{\mathrm{Ph}} \text { Line voltage THD } \\
\text { As a \% of fundamental }\end{array}$ & $\begin{array}{c}\text { I(current) THD } \\
\text { As a \% of fundamental }\end{array}$ \\
\hline 600 & 10.51 & 30.21 & 4.22 \\
900 & 9.50 & 29.33 & 4.32 \\
1050 & 9.66 & 28.93 & 4.42 \\
2100 & 8.37 & 28.05 & 4.47 \\
3000 & 7.84 & 27.85 & 4.43 \\
4200 & 7.95 & 27.35 & 4.45 \\
\hline
\end{tabular}

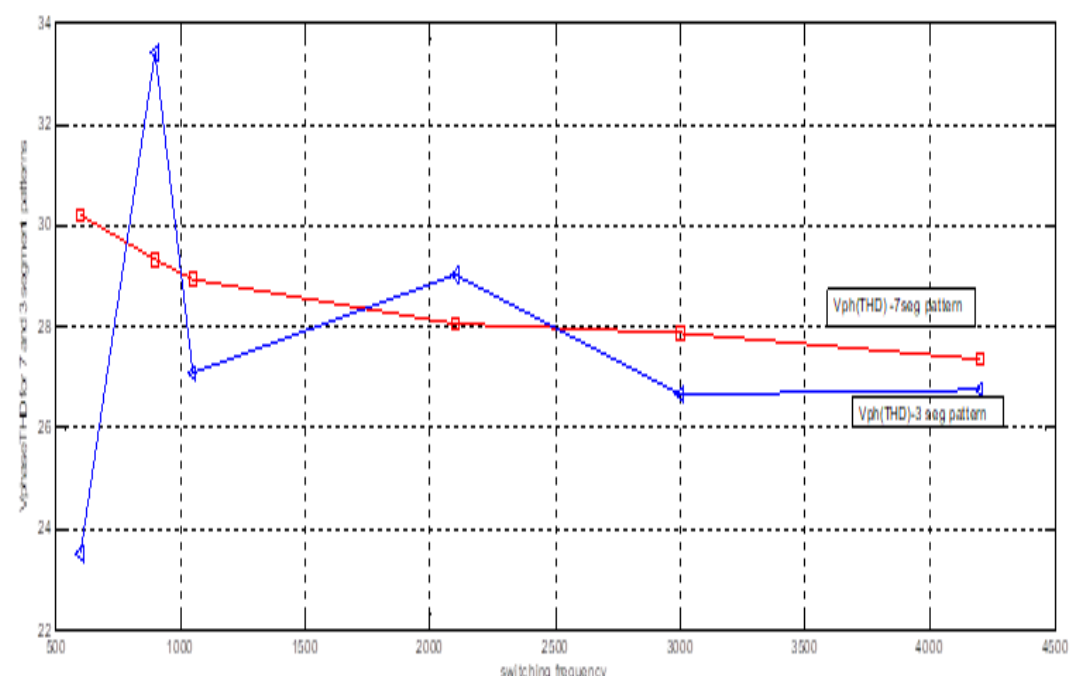

Figure 8. Phase Voltage THD at various inverter frequencies for 7- segment and 3- segment switching Patterns

From Figure 9 it is shown that the Line voltage THD and current THD decreases at higher inverter frequencies in case of three-segment switching pattern compared to seven-segment switching pattern.

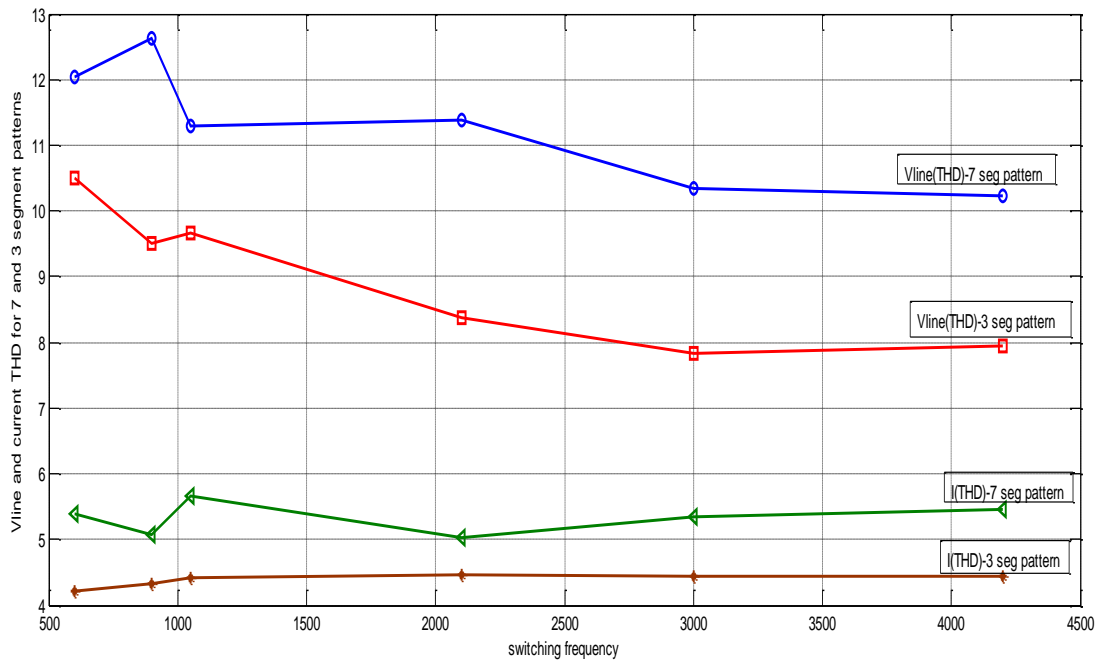

Figure 9. Line Voltage and current THDs at various inverter frequencies for 7- segment and 3- segment switching patterns 


\section{CONCLUSION}

This paper presents general SVPWM technique based on seven-segment and three-segment online switching patterns for $\mathrm{N}$-level inverter. The two switching patterns are simulated for five level cascaded inverter. One of the important feature of this technique is that,out of large number of switching states of the five level inverter, the desired switching states and most suitable redundant states are selected for the both sequence patterns such that, the technique is implemented online with no need of lookup table. In the threesegment switching sequence, the inverter equivalent frequency is 50\% higher than that of seven-segment, harmonics appear as sideband around high inverter frequency, and the magnitude of lower order harmonics is reduced for three segment giving lesser value of Line voltage and current THDs when compared to that of seven-segmentswitching pattern.

\section{REFERENCES}

[1] J. Rodríguez, J. Lai, and F. Peng, "Multi Level Converters: A Survey of Topologies, Controls and Applications", IEEE Trans. Ind. Electron., vol. 49, no. 4, pp. 724-738, Aug. 2002.

[2] P. Satish Kumar, J. Amarnath, S.V.L. Narasimham, "A Fast Space-vector Pulse with Modulation Method for Diodeclamped Multi-level Inverter Fed Induction Motor”, Asian Power Electronics Journal, vol. 4, no. 1, April 2010.

[3] P. Satish Kumar, "A New General Topology for Cascaded Multilevel Inverters with Increased Number of levels Based on Diagonal DC Source H-Bridge", International Journal of Advances in Electrical and Electronics Engoneering, vol. 3, no. 3, pp. 175-184, 2014.

[4] Sanmin Wei and Bin Wu, "A General Space Vector PWM control Algorithm for Multi-level inverters", IEEE 2003, pp. 562-568.

[5] Amit Kumar Gupta and Ashwin M. Khambadkone, "A General Space Vector PWM Algorithm for Multi Level Inverters, Including Operation in Overmodulation Range”, IEEE Transactions on Power Electronics, vol. 22, no. 2, March 2007.

[6] Anshuman Tripati, Khambadkone and S.K. Panda, "Direct Method of over Modulation with Integrated Closed Loop Stator Flux Vector Control", IEEE Trans. on Power Electronics, vol. 20, no. 5, pp. 1161-1168, Sep. 2005.

[7] B. Sirisha, P. Satish Kumar, N.Susheela, "Three Phase Two Leg Neutral Point Clamped Converter with output DC Voltage Regulation and Input Power Factor Correction”, International Journal of Power Electronics and Drive System (IJPEDS), vol. 2, no. 2, June 2012.

[8] A. Nabae, I.Takahashi, cd H. Akagi, "A New Neutral-point Clamped pwm Inverter", IEEE Trans. Ind. Appl., vol. 1A-17, no.5, pp.5 18-523, Sept/Oct 1982.

[9] B. Sirisha, P. Satish Kumar, "A Space Vector Pulse Width Modulation Technique for Five Level Cascaded HBridge Inverter Including Over Modulation Region with FPGA Implementation”, International Journal of power Electronics and Drives (IJPEDS), vol. 8, no. 3, September 2017.

[10] B. Sirisha, P. Satish Kumar, "Implementation of FPGA based Space Vector PWM Methodfor Five Level Cascaded Inverter", IEEE 7th Power India International Conference (PIICON 2016) at Bikaner Rajasthan, November 25-27 2016.

[11] B. Sirisha, P. Satish Kumar, "A Simplified Space Vector PWM for Cascaded H- Bridge Inverter including Over Modulation Operation", $13^{\text {th }}$ International IEEE India Conference INDICON 2016 at IISC, Bengaluru, India. December 16-18, 2016.

[12] D.W. Kang, Y.H. Lee, B.S. Suh, C.H. Choi, and D.S. Hyun, "A Carrier wave-based svpwm using Phase-voltage Redundancies for Multilevel H-bridge Inverter", International Conference on Industrial Electronics, Control, and Instrumentation (IECON), vol. 1, pp.324-329, 1999.

[13] N. Celanovic and D. Boroyevich, "A Fast Space Vector Modulation Algorithm for Multilevel Three Phase Converters", IEEE Trans on Industry Applications, vol. 37, no. 2, pp. 637-641, 2001.

[14] "Voltage Source Inverters with Phase-shifted Unipolar spwm", IEEE Ttrans. on Industry Applications, vol. 35, no. 5, pp. 1118-1123, 1999.

[15] D.W. Kang, Y.H. Lee, B.S. Suh, C.H. Choi, and D.S. Hyun, "A Carrier wave-based svpwm using Phase-voltage Redundancies for Multilevel H-bridge Inverter", International Conference on Industrial Electronics, Control, and Instrumentation (IECON), vol. 1, pp. 324-329, 1999.

[16] N. Celanovic and D. Boroyevich, "A Fast Space Vector Modulation Algorithm for Multilevel Three Phase Converters", IEEE Trans on Industry Applications, vol. 37, no. 2, pp.637-641, 2001.

[17] B.S. Suh, G. Sinha, M.D. Manjrekar, and T.A. Lipo, "Multilevel Power Conversion-an overview of Topologies and Modulation Strategies", International Conference on Optimization of Electrical and Electronic Equipment (optim), vol. 2, pp.101-105, 1998.

[18] Hu, Hongyan Wang, Yan Deng and Xiagning, “A Simple SVPWM Algorithm of Multilevel inverter", Power Electronics Specialistic Conference, Achen, 2004.

[19] M.L. Tolbert and F.Z. Peng, "Multi- Level converter for Large Electric Drives", IEEE Trans. Indus. Applica., vol. 35, no. 1, pp 36-44, 1999.

[20] B.S. Suh and D.S. Hvun, "A New N-Level High Voltage Inversion System”, IEEE Trans. on Industrial Electronics, vol. 44, no. 14, pp. 107-I 15, 1997.

[21] L. Yiqiao and C.O. Nwankpa, "A New Type of STATCOM based on Cascading Voltage Source Inverters with Phase-shifted Unipolar SPWM”, IEEE Trans. on Industry Applications, vol. 35, no. 5, pp. 1118-1123, 1999. 
[22] D.W. Kang, Y.H. Lee, B.S. Suh, C.H. Choi, and D.S. Hyun, "A Carrier wave-based SVPWM using Phase-Voltage Redundancies for Multilevel H-bridge Inverter", International Conference on Industrial Electronics, Control, and Instrumentation (IECON), vol. 1, pp 324-329, 1999.

[23] Krause, P. C., 'Simulation of Symmetrical Induction Machinery", IEEE Trans. Power Apparatus Systems, vol. PAS-84, no. 11, pp. 1038-1053, 1965.

[24] Ghani, S. N., "Digital Computer Simulation of Three-phase Induction Machine Dynamics - A Generalized Approach", IEEE Trans Industry Appl., vol. 24, no. 1, pp. 106-114, 1988.

\section{BIOGRAPHIES OF AUTHORS}

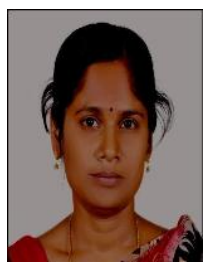

B. Sirisha obtained her B.E degree in Electrical \& Electronics Engineering from Osmania University and M.E degree from JNTU, Hyderabad and persuing Ph.D. in the area of multilevelinverters. She is currently working as Assistant Professor in Department of Electrical Engineering, University College of Engineering (Autonomous), Osmania University, Hyderabad, Telangana, India. Her research interests include Power Electronics, multilevel inverters and drives.

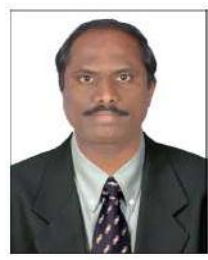

Dr. P. Satish Kumar was born in Karimnagar, Andhra Pradesh, INDIA in 1974. He obtained the B.Tech degree in electrical engineering from JNTU College of Engineering, Kakinada in 1996. He obtained M.Tech degree in power electronics in 2003 and Ph.D. in 2011 from JNTUH, Hyderabad. He has more than 16 years of teaching and research experience and presently working as Senior Assistant Professor in the Department of Electrical Engineering, University College of Engineering,Osmania University, Hyderabad, INDIA. He presented many research papers in various national and international journals and conferences. Achieved Award for Research Excellence and Best young teacher Award-2014.Holds UGC-Major Research Project and SERB(DST)-Research Projects on multilevel inverters. His research interests include Power Electronics Drives, Multilevel inverters, Matrix Converters and special machines. 